\title{
Depression, Anxiety, And Stress Among Adolescents In Kuantan And Its Association With Religiosity- A Pilot Study
}

\author{
Ahmad Safwan Mohamad ${ }^{1}$, Samsul Draman ${ }^{1}$, Mohd Aznan Md Aris ${ }^{1}$, Ramli Musa ${ }^{1}$, Razman Mohd Rus ${ }^{1}$, \& \\ Maszlee Malik ${ }^{2}$ \\ ${ }^{1}$ Kulliyyah of Medicine, International Islamic University Malaysia (IIUM) Kuantan \\ ${ }^{2}$ Kulliyyah of Islamic Revealed Knowledge and Human Science, IIUM Gombak
}

\begin{abstract}
Adolescence is a period of time when the development of personality and psychology is taking place. Studies have shown that religiosity can affect the mental health of a person. Many tools have been developed to assess religiosity of a person; one of them is the Santa Clara Strength of Religious Faith (SCSORF) scale. In this study, a translation and validation for SCSORF Malay Version (SCSORF-M) is done, and subsequently used to look for the association between religiosity and mental health in adolescents. Fifty questionnaire papers have been distributed to 50 students in secondary schools in district of Kuantan. The mean score for depression, anxiety, and stress are 5.83, 5.59, and 8.34 respectively. Only 10 (24.4\%) have no depression, 9 (22\%) have no anxiety, and $13(31.7 \%)$ have no stress. The mean score for SCSORF-M scale was 35.3 (range 25-40). Family income has shown to correspond negatively with the depression, anxiety, and stress, while religiosity has shown to be correlating negatively with depression and stress, but positive correlation with anxiety. SCSORF-M has positive convergent correlation with Duke's University Religiosity Index Malay Version (DUREL-M) in all domains. SCSORF-M has shown good Cronbach's alpha value (0.84). In conclusion, religiosity is an important factor to contribute to the outcome of mental health among adolescents. SCSORF-M can be used as an assessment tool for religiosity.
\end{abstract}

KEYWORDS: religiosity, mental health, adolescents, Santa Clara Strength of Religious Faith, Bahasa Melayu

\section{INTRODUCTION}

Neuropsychiatric disorders are currently estimated to contribute to $13 \%$ of the global burden of disease 1 . According to World Health Organization (WHO), mental health is defined as: "...the capacity of the individual, the group and the environment to interact with one another to promote subjective well-being, and optimal functioning, the use of cognitive, affective and relational abilities, towards the achievement of individual and collective goals consistent with justice". ${ }^{2}$

The study on mental health has started since hundreds of years ago. ${ }^{3}$ Many activities of daily living are affected by the mental health status of an individual. The modern medicine, which mainly referred to the western originated knowledge of medicine, is evolved from the secular worldview. Before the western civilization took place as a leading civilization, Muslim world has already contributed a lot in medicine. During this era, Muslim physician has never separated the physical and spiritual aspect of medicine. ${ }^{4}$ Avicenna (9721036) for example, had written in his magnum opus 'The Canon' that in medicine, there should not be

Corresponding author:

Samsul Draman

Kulliyyah of Medicine

International Islamic University Malaysia

Jalan Sultan Ahmad Shah, 25200 Kuantan, Pahang

Email: nurin@iium.edu.my any separation between the physical from the spiritual aspect, as it inter-relates with each other. Al-Kindi, who is believed to be the first who write regarding the Ilmu-Nufus, also described clearly regarding the relationship between the ruh (soul), belief, and the mental status. ${ }^{5}$ Al-Ghazali also has written in his 'Alchemy of Happiness' regarding the relationship between happiness and the inner-heart (soul).

After that, the gap between science and religion became widened. In 1969, Victor Sanua stated that, 'there are no scientific studies which show that religion is capable of serving mental health'. ${ }^{6}$ Only in the late nineteenth century, Jean Charcot and Sigmund Freud began to associate religion with hysteria and neurosis. ${ }^{7}$ Larson et al (1992), on the other hand, tried to revise Sanua's hypothesis by doing 2 systematic reviews, each in 1986 and $1992 .^{8}$ They found that about $72 \%$ of their 35 papers reviewed suggest a positive relationship between religiosity and good mental health. This contradicting finding had triggered many other researchers to explore more on the relationship between the mental health and faith/religiosity. Many measurement of religiosity scales have been developed since then, including the Santa Clara Strength of Religious Faith (SCSORF) questionnaire.

This study is intended to translate the SCSORF and validate the Santa Clara Strength of Religious Faith Malay Version (SCSORF-M), as well as to look at its 
IMJM Volume 17 Special Issue No 2

relationship with depression, anxiety, and stress in adolescent population.

\section{METHODOLOGY}

\section{Study Design}

This is a cross-sectional study by using a selfadministered questionnaire. Permission has been obtained from the Ministry of Education and Pahang Department of Education prior to that. A written consent from parents has been obtained following the protocol of Good Clinical Practice and ethic requirement. Participants have been briefed few days before to enable them to obtain the relevant socio-demographic information from their parents.

A special permission from the original author of Santa Clara Strength of Religious Faith (SCSORF), Thomas G Plante, was also acquired before the commencement of this study.

\section{Translation process of the SCSORF}

The translation process of SCSORF was carried out by four independent bi-lingual translators who are fluent in English and Malay. Forward translation was done by two Malay native speakers and backward translation was done by the other two Malay native speakers. The forward and back translated versions were reconciled and sentence by sentence revision was done. A harmonized version of Malay version of SCSORF (SCSORF-M) was produced.

The harmonized version is then reviewed by two physicians and one psychiatrist to ensure satisfactory face, semantic, criterion and conceptual equivalence.

\section{Validation process}

The finalized BM version (SCSORF-M) then was tested for its reliability and validity. Reliability in this study was determined by its internal consistency by looking at Cronbach's alpha values. Validity analysis has been done by using Convergent Validity Test with the scale that has been validated, which is the Malay Version of Duke University Religion Index (DUREL-M).

\section{Selection of respondents}

A group of students from Sekolah Menengah Kebangsaan Panglima Perang Tengku Muhammad (SMKPPTM) were approached with the assistance from the school counselor. Fifty students have agreed to participate. ${ }^{9}$

All the participants were bi-lingual. The participants were given the following questionnaires:

1. The Malay version of Depression, Anxiety, and Stress Scale (DASS-21)

2. The Malay version of DUREL (DUREL-M)

3. The Malay version of SCSORF (SCSORF-M)

\section{Research Tools}

Duke's University Religiosity Index Malay Version (DUREL-M)
DUREL is first published in 1997 in the Amarican Journal of Psychiatry. It is developed by a group of researchers in Duke's University, after intensive review of previous studies have been done in North Carolina and the study conducted by Hoge in Duke University Hospital ${ }^{10}$. It is used to measure religious commitment of the respondent. It consists of five items covering three major dimensions of religious commitment: organization religious activity (ORA, one item); non-organizational religious activity (NORA, one item); and intrinsic religiosity (IR, three items). ORA consists of public religious activities, such as frequency of attending religious services or participating in other group-related religious activity. NORA consists of religious activities performed in private, such as prayer or reading the Bible. IR is the degree of personal religious commitment or motivation. The DUREL has an overall score range from 5 to 27 . It was translated into the Malay language and has been validated ${ }^{11}$. Cronbach's a was good $(0.80) .{ }^{12}$

Depression, Anxiety, and Stress Scale-21 Malay Version (DASS-21)

DASS was developed by a group of researchers in University of New South Wales, Australia, around year 1995. It is a set of three self-report scales designed to measure the negative emotional states of depression, anxiety and stress. The original DASS consist of 42-item questionnaire, while the short version DASS21 consists of 21 items. DASS have been shown to have high internal consistency. It has been validated in various languages including Bahasa Malaysia. It also has good reliability, with very good Cronbach's alpha values of $0.84,0.74$ and 0.79 , respectively for depression, anxiety, and stress scale. ${ }^{13,14,15}$

Santa Clara Strength of Religious Faith (SCSORF)

SCSORF was developed by $\mathrm{Dr}$ Thomas G. Plante in 1997, after having clinical contact with religious patient. ${ }^{16}$ It is a brief $(10$-item, or five-item short form version), reliable, and valid self -report measure assessing strength of religious faith and engagement. It is suitable for use with multiple religious traditions (including Muslim) as well as for people without any interest in or affiliation with religious organizations or traditions and perspectives. The internal consistency of the scale have found corrections ranging from 0.94 to 0.97 using Cronbach Alpha's and split-half reliability scores ranging from 0.90 to $0.96 .{ }^{17}$ However, most of the study were conducted in Europe ${ }^{17}$.

\section{RESULTS}

There are fifty (50) questionnaire papers have been distributed to participants who have consented for enrolment in the study. Nine (9) of them have been rejected due to incomplete answer (8) and 1 was not returned. All 41 remaining papers have been analyzed by using SPSS Version 20 .

Out of 41 students, 8 (19.5\%) are from form 1 (13 years old), $10(24.4 \%)$ are from form 2 (14 years 
old), and 24 (56.1\%) are from form 4 (16 years old) students. 29 of them are female $(70.7 \%)$ while 12 (29.3\%) are male. Almost all participants are Muslim (95.1\%), while only $2(4.9 \%)$ are Buddhist. From 41 participants, majority of them $(61 \%)$ are coming from middle class group, with household income of RM1000-RM4999. 2 (4.8\%) of them are from lower income group (lower than RM1000), while 14 (34.2\%) are coming from upper middle and higher class, with household income of above RM5000 (Table 1).

Table I Demographic Distribution

\begin{tabular}{lll}
\hline Variables & No. & $\%$ \\
\hline Age (year) & 8 & 19.5 \\
13 & 10 & 24.4 \\
14 & 23 & 56.1 \\
16 & & \\
& & \\
Gender & 12 & 29.3 \\
Male & 29 & 70.7 \\
Female & & \\
& & \\
Religion & 39 & 95.1 \\
Islam & 0 & 0 \\
Hindu & 2 & 4.9 \\
Buddha & 0 & 0 \\
Christian & 0 & 0 \\
Others & & \\
& & \\
Family Income & & 17.1 \\
$<1000$ & 2 & 4.8 \\
1000-4999 & 25 & 61 \\
$5000-9999$ & 7 & 17.1 \\
$>9999$ & & \\
\hline
\end{tabular}

The mean score for depression, anxiety, and stress are $5.83,5.59$, and 8.34 respectively. Only 10 (24.4\%) have no depression, while $31(75.6 \%)$ have at least mild depression. The anxiety status of respondents shows that 9 (22\%) of them have no anxiety, while $32(88 \%)$ of them have at least mild anxiety. The status of stress shows that $13(31.7 \%)$ of them have no stress, while $28(68.3 \%)$ are suffering from at least mild stress (Table 2).
Table II: Distribution of Stress, Anxiety, and Stress

\begin{tabular}{lll}
\hline Domain & Mean (SD) & No. (\%) \\
\hline Depression & $5.83(3.52)$ & \\
Normal & & $10(24.4)$ \\
Mild & & $8(19.5)$ \\
Moderate & & $2(4.9)$ \\
Severe & & $3(7.3)$ \\
Extremely & & \\
Severe & & \\
Anxiety & $5.59(3.42)$ & $9(22.0)$ \\
Normal & & $8(19.5)$ \\
Mild & & $9(22.0)$ \\
Moderate & & $8(19.5)$ \\
Severe & & $7(17.1)$ \\
Extremely & & \\
Severe & & $13(31.7)$ \\
Stress & $8(19.5)$ \\
Normal & & $10(24.4)$ \\
Mild & & $10(24.4)$ \\
Moderate & & - \\
Severe & & \\
Extremely & & \\
Severe & & \\
\hline
\end{tabular}

For religiosity, the mean score for Santa Clara Strength of Religious Faith scale was 35.3 (range 25-40). The mean score for ORA is 4.07 (range 16), NORA is 4.24 (range 1-6), while IR is 12.66 (range 7-15) (Table III).

Table III Distribution of Religiosity

\begin{tabular}{lll}
\hline Scales & Range & Mean (SD) \\
\hline DUREL-M & & \\
$\quad \begin{array}{l}\text { Organized } \\
\text { Religiosity (ORA) }\end{array}$ & & $4.07(1.42)$ \\
$\quad \begin{array}{l}\text { Non-organized } \\
\text { Religiosity } \\
\text { (NORA) }\end{array}$ & $1-6$ & $4.24(1.39)$ \\
$\quad$ Intrinsic & $1-6$ & \\
$\quad$ Religiosity (IR) & $7-15$ & $12.66(2.18)$ \\
SCSORF & $25-40$ & $35.05(3.86)$ \\
\hline
\end{tabular}

Family income has shown to correspond negatively with the depression $(p=0.26)$, anxiety $(p=0.28)$, and stress $(p=0.65)$. The religiosity has shown to be correlating negatively with depression $(p=0.63)$ and stress $(\mathrm{p}=0.79)$, and having positive correlation with anxiety $(p=0.47)$. However, all are not statistically significant (Table 4 ). 
Table IV Relationship between Family Income and Religiosity with Mental Health

\begin{tabular}{llll}
\hline & Depression (Sig.) & Anxiety (Sig.) & Stress (Sig.) \\
\hline Family Income & $-0.18(0.26)$ & $-0.17(0.28)$ & $-0.07(0.65)$ \\
SCSORF & $-0.08(0.63)$ & $0.11(0.47)$ & $-0.04(0.79)$ \\
\hline
\end{tabular}

SCSORF-M has positive correlation with DUREL-M in all domains, with strong correlation with IR (Table 5). It also has shown good Cronbach's alpha value (0.84).

Table V Convergent Validity test for SCSORF-M

\begin{tabular}{llll} 
& ORA (Sig.) & NORA (Sig.) & IR (Sig.) \\
\hline SCSORF-M & $0.03(0.85)$ & $0.39(0.01)$ & $0.78(<0.01)$ \\
\hline
\end{tabular}

\section{DISCUSSION}

Religiosity and spirituality are important factors to determine the good outcome in life. However, it is very difficult to be measured objectively in a study. Many tools have been developed to estimate roughly regarding the level of religiosity/ spirituality of a person. SCSORF was developed to fill the research gap in providing a better understanding regarding religiosity and spirituality.

Mental health problem in adolescents in Malaysia is estimated to be $11.4 \%$ (NHMS 2015). ${ }^{18}$ In this pilot study, it is found that $75.6 \%$ of respondents are depressed, $88 \%$ are anxious, while $68.3 \%$ are stressed. However, it is understood that the limitation of this pilot study is the sample size, which can contribute to the result.

The religiosity level of respondents is above average, which the SCSORF gives mean score of 35.3 (max 40). Mean score achieved by using DUREL-M was also high, whereby ORA is 4.07 ( $\max$ 6), NORA was $4.24(\max 6)$, and IR was 12.66 ( $\max$ 15). This might be due to the formal religious and moral education which is given to the schooling students in Malaysia. Further study need to be done with larger sample size to identify the trend of religiosity among the secondary school students.

Although they are not statistically significant, the study has shown that the higher family income can be protective against depression, anxiety, and stress. Religiosity, on the other hand, is likely to be protective towards depression and stress, but interestingly, not for anxiety. However, this finding needs to be confirmed with further study with a larger sample size.

SCSORF-M has strong internal reliability, with Cronbach's alpha of 0.84 . It means that this tool can be used in adolescents and with multiracial and multi-religion background. This study also has proven that SCSORF-M is able to measure the religiosity likewise the DUREL-M. The strong correlation is found to be with the Intrinsic Religiosity from DUREL-M, which possibly means that SCSORF-M is more sensitive to measure the spirituality aspect.

Although the convergent correlation shows positive correlation with DUREL-M, it is recommended that further study can be made to compare it with other religiosity or spirituality measurement tools.

\section{CONCLUSION}

The Malay version of SCSORF displayed good internal reliability and convergent validity in measuring the religious commitment and strength among the students of SMKTPPTA. It could also be used for assessment of religiosity in the other Malaysian adolescents.

\section{ACKNOWLEDGEMENT}

We wish to extend our gratitude to all participants in this study and teachers of Sek Men Tengku Panglima Perang Tengku Muhammad, especially the counsellor and principal, for their cooperation.

\section{REFERENCES}

1. World Health Organization. The global burden of disease: 2004 Update. 2008.

2. World Health Organization. Mental health action plan 2013-2020. 2013.

3. Nasser M Psychiatry in Ancient Egypt. Psychiatr Bull [Internet]. 1987 Dec 1 [cited $2014 \mathrm{Nov}$ 18];11(12):420-2. Available from: http:// pb.rcpsych.org/cgi/doi/10.1192/pb.11.12.420

4. Speziale F Psychiatric Care in the Subcontinent. 2003; (March):2003.

5. Skinner R An Islamic approach to psychology and mental health. Ment Health Relig Cult [Internet]. 2010 Sep [cited 2014 Nov 18];13

(6):547-51. Available from: http:// www.tandfonline.com/doi/ abs/10.1080/13674676.2010.488441

6. Sanua VD Religion, mental health, and personality: A review of empirical studies. Am J Psychiatry 1969;125(9):1203-1213.

7. Bonelli RM, Koenig HG Mental disorders, religion 
and spirituality 1990 to 2010 : a systematic evidence-based review. J Relig Health [Internet]. 2013 Jun [cited 2014 Sep 10];52 (2):657-73. Available from: http:// www.ncbi.nlm.nih.gov/pubmed/23420279

8. Larson, D B, Sherrill, K A, Lyons, J S, Craigie, F C, Jr, Thielman, S B, Greenwold MA Associations between dimensions of religious commitment and mental health reported in the American Journal of Psychiatry and Archives of General Psychiatry: 1978-1989. Am J Psychiatry. 1992;149(4):557-559.

9. Connelly LM Pilot studies. Medsurg Nurs [Internet]. 2008;17(6):411-2. Available from: http://search.ebscohost.com/login.aspx? direct=true\&db=a9h\&AN=36085347\&site=ehost livefile://C:Idownloads \J\#301 Connelly MedSurgNursing 2008.pdf

10. Koenig HG, Büssing A The Duke University Religion Index (DUREL): A Five-Item Measure for Use in Epidemological Studies. Religions [Internet]. 2010 Dec 1 [cited 2014 Aug 5];1 (1):78-85. Available from: http:// www.mdpi.com/2077-1444/1/1/78/

11. Ms N, Aini A, Aa AS, Cg N Validity and Reliability of the Malay Version of Duke University Religion Index ( DUREL-M ) Among A Group of Nursing Student. Malaysian J Psychiatry Online Early. 2010;2(12).

12. Nurasikin MS, Khatijah $L$ a, Aini a, Ramli $M$, Aida S a, Zainal NZ, et al. Religiousness, religious coping methods and distress level among psychiatric patients in Malaysia. Int J Soc Psychiatry [Internet]. 2013 Jun [cited 2014 Oct 27];59(4):332-8. Available from: http:// www.ncbi.nlm.nih.gov/pubmed/22408116

13. Nieuwenhuijsen K, Boer AGEM De, Verbeek JHAM, Blonk RWB, Dijk FJH Van. The Depression Anxiety Stress Scales (DASS): detecting anxiety disorder and depression in employees absent from work because of mental health problems. Occup Environ Med. 2003; (phase 2):77-83.

14. Ramli M1, Salmiah M.A 2 Nam validation and psychometric properties of Bahasa Malaysia version of the depression anxiety and stress scales (Dass) among diabetic patients. Malaysian J Psychiatry Online Early. 2009;1-7.

15. Musa R, Fadzil MA, Zain Z Translation, validation and psychometric properties of Bahasa Malaysia version of the Depression Anxiety and Stress Scales ( DASS ). Asean J Psychiatry. 2007;8(2):82-9.

16. Universal A, Orientation R, In- RL, Sciences B, Clara S. Reliability and Validity of the Santa Clara Strength of Religious Faith Questionnaire. Pastoral Psychol. 1997;45(6):429-37.

17. Plante TG The Santa Clara Strength of Religious Faith Questionnaire: Assessing Faith Engagement in a Brief and Nondenominational Manner. Religions [Internet]. 2010 Oct 29 [cited 2014 Sep 26];1(1):3-8. Available from: http:// www.mdpi.com/2077-1444/1/1/3/

18. Malaysia $M$ of $\mathrm{H}$ National Health \& Morbidity Survey 2015 (NHMS 2015). 2015. 
